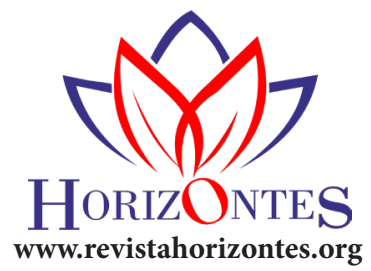

\title{
La mediación en las instituciones de educación superior. Estudio comparado entre España, Perú y Ecuador
}

\author{
Mediation in higher education institutions. Comparative study between Spain, Perú and Ecuador \\ Mediação em instituições de ensino superior. Estudo comparativo entre Espanha, Perú e Equador
}

$\begin{array}{rr}\text { Ingrid Liz Muñoz Feraud } & \text { Lenin Mendieta Toledo } \\ \text { ingrid.munozf@ug.edu.ec } & \text { lenin.mendietat@ug.edu.ec } \\ \text { https://orcid.org/0000-0002-6134-6158 } & \text { https://orcid.org/0000-0002-8385-898X } \\ \text { dad de Guayaquil, Guayaquil-Ecuador } & \text { Universidad de Guayaquil, Guayaquil-Ecuador }\end{array}$

Artículo recibido 20 de julio 2021, arbitrado y aceptado 11 de agosto 2021 y publicado 13 de diciembre 2021

\section{RESUMEN}

El presente trabajo de investigación tiene como objetivo comparar los sistemas de mediación que se utilizan en universidades de España, Perú y Ecuador, es un estudio comparado de las leyes, normas y reglamentos de tres diferentes países. El resultado observado es que, en las instituciones educativas superiores estudiadas de España, Perú y Ecuador, existen similitudes y diferencias en cuanto a los procesos de la resolución de problemas, se destaca que tanto España como Perú tienen un grado de similitud en cómo resolver los conflictos a través de la mediación interviniendo el Defensor Universitario, mientras que en Ecuador los problemas se manejan por una comisión del debido proceso.

Palabras clave: Mediación; Conflictos; Educación comparada; Educación superior

ABSTRACT

RESUMO

The present research work aims to compare the mediation systems used in some universities in Spain, Peru and Ecuador, in which a comparative study of thelaws, rules and regulations of three universities in different countries has been carried out. The observed result is that, in the higher educational institutions studied in Spain, Peru and Ecuador, there are similarities and differences in terms of problem-solving processes, it is highlighted that both Spain and Peru have a degree of similarity in how to solve problems. Conflicts through mediation, intervening by the University Defender, while in Ecuador problems are handled by a due process commission.

Key words: Mediation; Conflicts; Comparative education; Higher education
O presente trabalho de pesquisa tem como objetivo comparar os sistemas de mediação utilizados em algumas universidades da Espanha, Peru e Equador, nos quais foi realizado um estudo comparativo das leis, normas e regulamentos de três universidades de diferentes países. O resultado observado é que, nas instituições de ensino superior estudadas na Espanha, Peru e Equador, existem semelhanças e diferenças em termos de processos de resolução de problemas, destaca-se que tanto a Espanha quanto o Peru apresentam algum grau de semelhança na resolução de problemas. Conflitos por meio de mediação, com intervenção do Defensor da Universidade, enquanto no Equador os problemas são tratados por uma comissão de devido processo.

Palavras-chave:

Mediação; Conflitos; Educação comparada; Educação superior 


\section{INTRODUCCIÓN}

En las dos últimas décadas del siglo XX surge el término de mediación como un mecanismo alternativo de solución de conflictos, el que ha sido acogido por organizaciones para resolver alguna discrepancia en las relaciones interpersonales, lo que ha impedido que éstas sean armónicas, más aún, en los contextos universitarios, que favorezca el diálogo y la integración de la comunidad. Alcover (2019) sostiene que la mediación es una forma de solución de conflictos de cualquier naturaleza, cuya finalidad es dar por terminado el mismo, con la intervención de un tercero imparcial, que trabaja el conflicto y trata por distintos medios de establecer relaciones futuras a través del diálogo. Por otra parte, Alcover indica que es necesario fomentar la cultura de la mediación como una alternativa en los espacios o contextos universitarios, que les permitan a las partes involucradas en los conflictos afrontarlos y resolverlos de forma dialógica. El objetivo fue comparar los sistemas de mediación que se utilizan en universidades de España, Perú y Ecuador.

\section{METODOLOGÍA}

La metodología de este trabajo proviene de la educación comparada, la cual es parte de las Ciencias de la Educación (Schriewer, 2002, p. 13). La educación compara que tuvo sus primeras luces hacia finales del siglo XVIII y principios de siglo XIX (Schriewer, 2002, p. 14). El presente es un estudio en donde las revisiones bibliográficas de leyes, protocolos y procesos que se llevan a cabo en instituciones de educación superior de tres países, tales como España, Perú y Ecuador, permite que éstos se puedan comparar para establecer las similitudes y diferencias en cuanto al mecanismo alternativo de solución de conflictos a través de la mediación y la figura del Defensor Universitario que existen en las instituciones de educación superior de estos países.

El recorrido del ensayo transita por algunos conceptos de mediación, se revisó la mediación en España, Perú y Ecuador y su aplicación en algunas instituciones educativas del nivel superior, colegimos cómo están constituidas y cuáles son las competencias de las defensorías universitarias en cada país, se hace una breve discusión y se realizan las conclusiones en donde se detalla a través de cuadros comparativos las similitudes y diferencias que existen en las tres instituciones de educación superior.

\section{DESARROLLO Y DISCUSIÓN}

\section{El concepto de mediación según la apreciación de algunos autores}

La mediación, surge a mediados del siglo XX, es en ese momento histórico en el que podemos decir que aparece la mediación que se aplica profesionalmente en la actualidad (Miranzo, 2010). Dada su complejidad, es un coadyuvante en el proceso comunicativo humano, cuyos atributos son la confidencialidad, espontaneidad y discrecionalidad (Gaddi, 2016), realizada a través de una metodología enriquecida de estrategias y técnicas en el cual las partes involucradas, mediante la intervención y participación de un mediador imparcial e independiente, determinan, enuncian y estudian los casos que ocasionan las controversias, con el objetivo de desarrollar y plantear sus propias alternativas o soluciones que les permitan mejorar 
la relaciones entre las partes (Alcove, 2010). Siendo necesario, que los implicados estén motivados y en total acuerdo de la mediación para resolver sus conflictos y estén comprometidos de mantener el respeto durante y después de este proceso (De Armas, 2003).

\section{La mediación en España y su aplicación en las instituciones educativas}

En España, la figura del Defensor Universitario aparece en la Disposición adicional decimocuarta de la Ley Orgánica 6/2001, de 21 de diciembre, de Universidades, con carácter obligatorio, para que esta institución garantice el respeto de los derechos y libertades de los profesores, estudiantes y personal de administración y de servicios, ante la forma de actuar de los órganos y servicios universitarios, para que coadyuve a la mejora de la calidad universitaria en todos los ámbitos de acción, debiendo las Universidades establecer en su estructura organizativa la figura del Defensor Universitario e incorporarlas en los Estatutos de las Universidades esta función (B.O.E, 2001).

Mediante el Real Decreto 1791/2010 del 30 de diciembre de 2010 (BOE, 2010), se aprueba el Estatuto del Estudiante Universitario y en él se concibe la forma de cómo garantizar la efectiva tutela de los derechos de los estudiantes, recayendo este quehacer jurídico en el Defensor Universitario. Contemplando, además, dentro de esta normativa, específicamente en el artículo 46, que el Defensor Universitario no sólo tiene a su alcance vigilar por el respeto a los derechos y las libertades de los estudiantes, sino que también de los profesores y personal de administración y servicios. Esta disposición jurídica, le otorga a los Defensores Universitarios ciertas atribuciones y competencias, teniendo que asumir tareas de mediación, conciliación y buenos oficios, conforme a los Estatutos de las Universidades y a las disposiciones de desarrollo, para promover la convivencia, la cultura de la ética, la corresponsabilidad y las buenas prácticas.

Adicionalmente el Real Decreto 1791/2010 del 30 de diciembre de 2010 (BOE, 2010), otorga la competencia de asesorar a los estudiantes sobre los procedimientos administrativos que existan para la formulación de sus reclamaciones, sin perjuicio de las competencias de otros órganos administrativos, consecuentemente, los discentes podrán acudir ante este defensor en el caso de que se sientan lesionados en sus derechos y libertades en los términos establecidos en los Estatutos de las Universidades. Según estos Reales Decretos, el Defensor Universitario debe cumplir una gama de funciones como de roles, y su papel más importante dentro de la mediación es el de mediador, que consiste en ser el ente interventor en el procedimiento alternativo.

Las principales características de los mediadores son: 1) ser capaz de abrir el diálogo, para que los involucrados en el conflicto puedan clarificar sus intereses y alcanzar una solución justa para todos. 2) motivar a las partes para que encuentren un punto de comunicación. 3) escuchar activamente los problemas. 4) retroalimentar los planteamientos de los involucrados en el conflicto para que lleguen a un acuerdo. (Universidad Autónoma de Nuevo León, 2019).

Tomando en consideración el procedimiento interno que de acuerdo a la ley le dan las universidades, se ha tomado como referencia los Estatutos de la Universidad de Málaga, institución pública universitaria ubicada en la ciudad de Andalucía, que fuera aprobado mediante Decreto 
464/2019 del 14 de mayo de 2019 (BOJA, 2019), en el cual se establece los mecanismos de regulación y funcionamiento de la Defensoría, considerado como un órgano unipersonal de garantía y control, en el cual se determina:

Que las actuaciones del titular de la defensoría serán hacia la mejora de la calidad universitaria en todos los ámbitos, debiendo proteger el respeto a los derechos y las libertades del profesorado, del estudiante y del personal de administración y servicios, ante el proceder de los organismos y servicios de la institución.

El puesto de la Defensoría será desempeñado por una persona integrante de la comunidad universitaria con vinculación permanente, de prestigio y trayectoria profesional. Su función será incompatible con el desempeño de cualquier otro órgano unipersonal y con la pertenencia a cualquier órgano colegiado o de representación de la Universidad.

Gozará de independencia y autonomía, porque no estará sometida a mandato alguno de cualquier instancia universitaria.

Ostentará rango de Vicerrectorado como forma protocolaria en el ejercicio de la defensoría.

La elección del defensor universitario corresponderá al Claustro, a propuesta del Rector, por mayoría simple y su mandato coincidirá con el órgano colegiado.

La Defensoría Universitaria recibirá las quejas que tramitará o rechazará de forma motivada (Tabla $1)$.

Así mismo, en el Decreto 464/2019 del 14 de mayo de 2019 (BOJA, 2019) se establece las competencias del mediador, tales como: Recabar información de las distintas instancias universitarias para el cumplimiento de sus fines; solicitar la comparecencia de las personas responsables de cualquier órgano universitario; asistir a las reuniones de los órganos colegiados en relación a las actuaciones que lleve a efecto; elaborar informes que le sean solicitados y efectuar propuestas que crea apropiada para la solución de los conflictos; desarrollar labores de mediación y conciliación cuando se creyere necesario y el caso lo amerite; todos los órganos de la comunidad universitaria están obligados a auxiliar con carácter preferente y urgente, a la Defensoría universitaria en sus investigaciones y valoraciones; el defensor rendirá cuenta ante el Claustro de la gestión realizada, de manera anual, el mismo que debe ser difundido; para el funcionamiento de la Defensoría, el Consejo de Gobierno deberá aprobar un reglamento en el que se estipulará los medios humanos, presupuesto y materiales necesarios para el desempeño de las actividades; no se incluirá en el examen individual por quejas que estén pendiente de resolución judicial, sin embargo, tomará en cuenta en la investigación sobre los problemas generales de las quejas presentadas; de acuerdo con el Reglamento de Defensor de la comunidad universitaria (Universidad de Málaga, 2013), se estipula que el tiempo perentorio para el ejercicio del cargo será de cuatro años, pudiendo ser reelegido. 
Tabla 1. Constitución de la Defensoría Universitaria.

\begin{tabular}{|c|c|c|c|c|c|c|c|}
\hline $\begin{array}{l}\text { Régimen jurídico } \\
\text { de la gobernanza } \\
\text { universitaria }\end{array}$ & $\begin{array}{c}\text { Estructura orgánica } \\
\text { universitaria }\end{array}$ & $\begin{array}{l}\text { Representado } \\
\text { por }\end{array}$ & Periodo & Rol & $\begin{array}{l}\text { Labor por } \\
\text { realizar }\end{array}$ & $\begin{array}{l}\text { Forma de } \\
\text { lección }\end{array}$ & $\begin{array}{l}\text { Forma de } \\
\text { actuar }\end{array}$ \\
\hline $\begin{array}{l}\text { Constitución } \\
\text { Española. } \\
\text { Ley Orgánica de } \\
\text { Universidades. } \\
\text { Estatuto de la } \\
\text { Universidad. } \\
\text { Reglamento } \\
\text { del Defensor } \\
\text { Universitario. }\end{array}$ & $\begin{array}{l}\text { Órgano } \\
\text { unipersonal. } \\
\text { Ostentará } \\
\text { rango de } \\
\text { Vicerrectorado } \\
\text { como forma } \\
\text { protocolaria en } \\
\text { el ejercicio de la } \\
\text { defensoría. }\end{array}$ & $\begin{array}{l}\text { Defensor } \\
\text { Universitario. } \\
\text { Puesto que será } \\
\text { desempeñado } \\
\text { por un integrante } \\
\text { de la comunidad } \\
\text { universitaria } \\
\text { con vinculación } \\
\text { permanente, de } \\
\text { prestigio } \\
\text { y trayectoria } \\
\text { profesional. }\end{array}$ & $\begin{array}{l}4 \text { años y existe } \\
\text { reelección. }\end{array}$ & $\begin{array}{l}\text { Garantizar y } \\
\text { proteger los } \\
\text { derechos y las } \\
\text { libertades del } \\
\text { profesorado, } \\
\text { estudiantes, } \\
\text { personal de } \\
\text { administración } \\
\text { y servicios. }\end{array}$ & $\begin{array}{l}\text { Mediación y } \\
\text { conciliación, } \\
\text { previa aceptación } \\
\text { de las partes. }\end{array}$ & $\begin{array}{l}\text { Corresponde } \\
\text { al Claustro } \\
\text { Universitario, a } \\
\text { propuesta del } \\
\text { Rector, por } \\
\text { mayoría simple } \\
\text { y su mandato } \\
\text { coincidirá con el } \\
\text { órgano colegiado. }\end{array}$ & $\begin{array}{l}\text { Gozará de } \\
\text { independencia } \\
\text { y autonomía, no } \\
\text { estará sometida a } \\
\text { mandato alguno de } \\
\text { cualquier instancia } \\
\text { universitaria. } \\
\text { Con rendición de } \\
\text { cuentas. }\end{array}$ \\
\hline
\end{tabular}


La mediación en Perú y su aplicación en las instituciones educativas

La Ley 30220 o Ley Universitaria (Congreso de la República, 2014), esta ley, según Cepeda (2019) establece ciertas innovaciones que pretenden mejorar el funcionamiento de las universidades del Perú, como es la creación de la Oficina de Defensoría Universitaria (ODU), cuya misión es tutelar los derechos individuales de los miembros de la comunidad universitaria, sin embargo, el autor comenta que pese al establecimiento de esta Ley es necesario analizar las funciones de la ODU y las condiciones para su funcionamiento, mismas que pueden ser perfectibles.

En el Artículo 133 de la norma enunciada (Congreso de la República, 2014), establece que:

La Defensoría Universitaria es la instancia encargada de la tutela de los derechos de los miembros de la comunidad universitaria y vela por el mantenimiento del principio de autoridad responsable. Es competente para conocer las denuncias y reclamaciones que formulen los miembros de la comunidad universitaria vinculadas con la infracción de derechos individuales. El Estatuto de la universidad establece los mecanismos de regulación y funcionamiento de la Defensoría. No forman parte de la competencia de la Defensoría las denuncias vinculadas con derechos de carácter colectivo, derechos laborales, medidas disciplinarias, evaluaciones académicas de docentes $\mathrm{y}$ alumnos y las violaciones que puedan impugnarse por otras vías ya establecidas en la presente Ley, así como en el Estatuto y los reglamentos de cada universidad.

Ante este precepto jurídico, se puede determinar que en los estatutos de cada universidad peruana se debe contemplar los mecanismos que permitan la regularización y funcionamiento de la Oficina de la Defensoría Universitaria, y en este sentido, para desarrollar este estudio comparativo se tomará como referencia la Universidad César Vallejo, institución con personería jurídica de derecho privado, ubicada en la ciudad de Trujillo, cuya existencia se dio el 12 de noviembre de 1991 mediante decreto de Ley de creación de la Universidad César Vallejo (Universidad César Vallejo, 1991).

En el Estatuto de la Universidad César Vallejo S.A.C. se determina que, dentro de la estructura orgánica de esa entidad, la Oficina de la Defensoría Universitaria se encuentra bajo el Órgano de Línea del Vicerrectorado de Bienestar Universitario, y en el Art. 81 del (Universidad César Vallejo, 2017) prescribe:

La defensoría Universitaria es el órgano encargado de la tutela de los derechos de los miembros de la comunidad universitaria y vela por el mantenimiento del principio de autoridad responsable, es competente para conocer la denuncias y reclamaciones que formulen los miembros de la comunidad universitaria vinculadas con la infracción de derecho individuales. Estará a cargo de un director designado por la Junta General de Accionistas. Sus funciones y atribuciones serán desarrollados en el Reglamento específico (p. 16).

Se establece en que una de las características más importantes de los defensores universitarios, en los ámbitos iberoamericano, anglosajón y europeo, es la mediación como estrategias para resolver los conflictos que se puedan dar entre compañeros, estudiantes y profesores o entre profesores y autoridades académicas antes de recurrir a procesos judiciales o administrativos que es lo que se pretende 
prevenir porque son procesos lentos, onerosos y con soluciones impuestas. (Agup2). (Tabla 2 y 3 ).

En el Art. 94 del Reglamento General de la (Universidad César Vallejo, 2017) se estipula que la Dirección de la Defensoría Universitaria es la encargada de tutelar los derechos de los miembros de la comunidad universitaria y velar por el mantenimiento del principio de autoridad responsable. Está a cargo de un director designado por el directorio el cual depende jerárquicamente del Rector (p. 18).

Así mismo, en el Art. 95 del mismo cuerpo legal, se declara cuáles serán las funciones del Defensor Universitario, cuales son:

1. Es competente para conocer las denuncia y reclamaciones que formulen los miembros de la comunidad universitaria vinculadas con la infracción de derechos individuales.

2. Tutelar los derechos de los miembros de la comunidad universitaria.
3. Velar por el mantenimiento del principio de la autoridad responsable.

4. Proponer los reglamentos o sus modificaciones que resulten necesarios para mejorar la gestión de su área al Vicerrectorado correspondiente.

5. Otras que le encargue el Rector, así como las establecidas en los reglamentos de la Universidad (p. 18).

No forman parte de la competencia de la defensoría las denuncias vinculadas con derechos de carácter colectivo, derechos laborales, medidas disciplinarias, evaluaciones académicas de docentes y estudiantes y las violaciones que puedan impugnarse por otras vías ya establecidas en la Ley Universitaria, así como en el Estatuto y los Reglamentos de la Universidad. 
Tabla 2. Constitución de la Defensoría Universitaria.

\begin{tabular}{|c|c|c|c|c|c|c|c|}
\hline $\begin{array}{l}\text { Régimen jurídico } \\
\text { de la gobernanza } \\
\text { universitaria }\end{array}$ & $\begin{array}{l}\text { Estructura orgánica } \\
\text { universitaria }\end{array}$ & $\begin{array}{l}\text { Representado } \\
\text { por }\end{array}$ & Periodo & Rol & $\begin{array}{l}\text { Labor por } \\
\text { realizar }\end{array}$ & $\begin{array}{l}\text { Forma de } \\
\text { lección }\end{array}$ & $\begin{array}{l}\text { Forma de } \\
\text { actuar }\end{array}$ \\
\hline $\begin{array}{l}\text { Constitución } \\
\text { Política del Perú. } \\
\text { Ley Universitaria } \\
\text { Ley No. } 30220 . \\
\text { Estatuto de la } \\
\text { Universidad. } \\
\text { Reglamento } \\
\text { General de la } \\
\text { Universidad. }\end{array}$ & $\begin{array}{l}\text { Órgano de } \\
\text { Línea del } \\
\text { Vicerrectorado } \\
\text { de Bienestar } \\
\text { Universitario. } \\
\text { Dirección de } \\
\text { Defensoría } \\
\text { Universitaria. }\end{array}$ & $\begin{array}{l}\text { Defensor } \\
\text { Universitario. } \\
\text { Puesto que será } \\
\text { desempeñado } \\
\text { por un director } \\
\text { designado por el } \\
\text { directorio de la } \\
\text { unta General } \\
\text { de Accionistas, } \\
\text { depende } \\
\text { jerárquicamente } \\
\text { del Rector. }\end{array}$ & No se indica. & $\begin{array}{l}\text { Tutelar los } \\
\text { derechos de los } \\
\text { miembros de } \\
\text { la comunidad } \\
\text { universitaria } \\
\text { y velar por el } \\
\text { mantenimiento } \\
\text { del principio } \\
\text { de autoridad } \\
\text { responsable. }\end{array}$ & $\begin{array}{l}\text { No se aborda } \\
\text { la mediación. }\end{array}$ & $\begin{array}{l}\text { Designación } \\
\text { corresponde } \\
\text { a la Junta } \\
\text { General de } \\
\text { Accionistas. }\end{array}$ & $\begin{array}{l}\text { Dependerá } \\
\text { jerárquicamente } \\
\text { del Rector. }\end{array}$ \\
\hline
\end{tabular}


La mediación en Ecuador y su aplicación en las instituciones educativas

En la (Congreso Nacional, 2008) en su Art. 355, se prescribe que:

El Estado reconocerá a las universidades y escuelas politécnicas autonomía académica, administrativa, financiera y orgánica, acorde con los objetivos del régimen de desarrollo y los principios establecidos en la Constitución. Se reconoce a las universidades y escuelas politécnicas el derecho a la autonomía, ejercida y comprendida de manera solidaria y responsable. Dicha autonomía garantiza el ejercicio de la libertad académica y el derecho a la búsqueda de la verdad, sin restricciones; el gobierno y gestión de sí mismas, en consonancia con los principios de alternancia, transparencia y los derechos políticos; y la producción de ciencia, tecnología, cultura y arte. La autonomía no exime a las instituciones del sistema de ser fiscalizadas, de la responsabilidad social, rendición de cuentas y participación en la planificación nacional (p. 104).

Por otra parte, la Ley Orgánica de Educación Superior (LOES, 2016) estipula en su artículo 18, el ejercicio de la autonomía responsable que ejercen las universidades y escuelas politécnicas consisten en:

a) La independencia para que los profesores e investigadores de las universidades $y$ escuelas politécnicas ejerzan la libertad de cátedra e investigación;

b) La libertad de expedir sus estatutos en el marco de las disposiciones de la presente Ley;

c) La libertad en la elaboración de sus planes y programas de estudio en el marco de las disposiciones de la presente Ley; d) La libertad para nombrar a sus autoridades, profesores o profesoras, investigadores o investigadoras, las y los servidores y las y los trabajadores, atendiendo a la alternancia y equidad de género, de conformidad con la Ley;

e) La libertad para gestionar sus procesos internos;

f) La libertad para elaborar, aprobar y ejecutar el presupuesto institucional. Para el efecto, en el caso de instituciones públicas, se observarán los parámetros establecidos por la normativa del sector público;

g) La libertad para adquirir y administrar su patrimonio en la forma prevista por la Ley;

h) La libertad para administrar los recursos acordes con los objetivos del régimen de desarrollo, sin perjuicio de la fiscalización a la institución por un órgano contralor interno o externo, según lo establezca la Ley; e,

i) La capacidad para determinar sus formas $y$ órganos de gobierno, en consonancia con los principios de alternancia, equidad de género, transparencia y derechos políticos señalados por la Constitución de la República, e integrar tales órganos en representación de la comunidad universitaria, de acuerdo con esta Ley y los estatutos de cada institución.

Las normativas jurídicas establecidas en Ecuador referente a las instituciones educativas superiores no tienen regularizados jurídicamente el mecanismo de la mediación como una forma de resolver los conflictos que surgen dentro de la 
comunidad universitaria, y para poner un ejemplo, en este estudio investigativo, se ha tomado como referencia a la Universidad de Guayaquil, que es la entidad educativa superior más grande y antigua del país. La Universidad de Guayaquil, fue fundada el 1 de diciembre de 1867, se encuentra ubicada en la ciudad de Guayaquil, Provincia del Guayas-Ecuador, institución de educación pública, y de acuerdo con la normativa jurídica goza de autonomía responsable y tiene la potestad de expedir sus propios estatutos.

En el Estatuto de la Universidad de Guayaquil (2019) en su Art. 212 determina que, en los casos de conflictos con los servidores públicos, esto es, personal administrativo, se procederá de acuerdo con la Ley Orgánica del Servicio Público; en el de los trabajadores se observará lo estipulado en el Código del Trabajo, y el de los profesores, lo señalado en la Ley Orgánica de Educación Superior con sus respectivos reglamentos.

De lo que se puede colegir, que en ninguno de los tres casos existe la figura del Defensor Universitario que permita la mediación y conciliación, frente a los problemas que pudieran existir dentro de la comunidad universitaria. Lo que sí existe, que para la defensa de los actores inmersos en el conflicto deberán recurrir a la Comisión del Debido Proceso, que es designado por la autoridad nominadora de la institución, en los casos de los profesores, estudiantes $\mathrm{y}$ autoridades que sean denunciadas, mas no de los servidores administrativos y de servicios. (Tabla 3 ). 
Tabla 3. Constitución de la Defensoría Universitaria: Proceso para la resolución de los conflictos profesores, autoridades y estudiantes.

\begin{tabular}{|c|c|c|c|c|c|c|c|}
\hline $\begin{array}{c}\text { Régimen jurídico } \\
\text { de la gobernanza } \\
\text { universitaria }\end{array}$ & $\begin{array}{c}\text { Estructura orgánica } \\
\text { universitaria }\end{array}$ & $\begin{array}{c}\text { Representado } \\
\text { por }\end{array}$ & Periodo & Rol & $\begin{array}{l}\text { Labor por } \\
\text { realizar }\end{array}$ & $\begin{array}{l}\text { Forma de } \\
\text { lección }\end{array}$ & $\begin{array}{l}\text { Forma de } \\
\text { actuar }\end{array}$ \\
\hline $\begin{array}{l}\text { Constitución de } \\
\text { la República del } \\
\text { Ecuador. } \\
\text { Ley Orgánica } \\
\text { de Educación } \\
\text { Superior. }\end{array}$ & $\begin{array}{l}\text { Consejo } \\
\text { Universitario. }\end{array}$ & $\begin{array}{l}\text { Comisión del } \\
\text { Debido Proceso, } \\
\text { designado por } \\
\text { el Consejo } \\
\text { Universitario. }\end{array}$ & Permanente. & $\begin{array}{l}\text { Garantizar el } \\
\text { debido proceso } \\
\text { establecido en la } \\
\text { Constitución de } \\
\text { la República del } \\
\text { Ecuador en su } \\
\text { Art. } 76 .\end{array}$ & $\begin{array}{l}\text { La medición } \\
\text { se lleva de } \\
\text { manera empírica, } \\
\text { por personas } \\
\text { que no conocen } \\
\text { sobre el tema. }\end{array}$ & $\begin{array}{l}\text { Designados por } \\
\text { los miembros } \\
\text { del Consejo } \\
\text { Universitario. }\end{array}$ & $\begin{array}{l}\text { Dependerá } \\
\text { jerárquicamente } \\
\text { del Rector. }\end{array}$ \\
\hline $\begin{array}{l}\text { Estatuto de la } \\
\text { Universidad. }\end{array}$ & & & & & & & \\
\hline $\begin{array}{l}\text { Reglamento de } \\
\text { Sanciones. }\end{array}$ & & & & & & & \\
\hline
\end{tabular}


En España y Perú, pese a que existe el organismo de la defensoría universitaria, en ningún apartado normativo legal de los estudiados se establece cuál debería ser el perfil del defensor, para que pueda mediar, ya que es una función muy delicada y se requiere de ciertas experticias en la utilización de estrategias y técnicas que permita llevar a cabo la mediación y conciliación (Alcover, 2019).

\section{Régimen jurídico de la gobernanza universitaria}

En los tres países existen artículos en sus constituciones, estatutos y leyes universitarias, reglamentos del defensor universitario (en Ecuador no existe, sin embargo, existe el reglamento de sanciones del debido proceso) que garantizan la intervención y mediación de conflictos. (Tabla 5).

\section{Estructura orgánica universitaria}

En España, en la Universidad de Málaga, existe un Órgano unipersonal, llevado por el vicerrectorado, en Perú, en la Universidad César Vallejo, existe el Órgano de Línea del Vicerrectorado de Bienestar Universitario y la Dirección de Defensoría Universitaria; en Ecuador en la Universidad de Guayaquil, existe el Consejo Universitario que regula de forma centralizada los debidos procesos disciplinarios.

\section{Representado por}

En España, existe el Defensor Universitario. Puesto que será desempeñado por un integrante de la comunidad universitaria con vinculación permanente, de prestigio y trayectoria profesional; en Perú existe el Defensor Universitario. Puesto que será desempeñado por un director designado por el directorio de la Junta General de Accionistas, depende jerárquicamente del Rector; en Ecuador no existe el Defensor Universitario, existe la Comisión del Debido Proceso, designado por el Consejo Universitario.

\section{Periodo}

En España tiene un periodo de desempeño de cuatro años con reelección; en Perú, no se indica y en Ecuador no existe.

\section{Rol}

En la Universidad de Málaga, garantiza y protege los derechos y las libertades del profesorado, estudiantes, personal de administración y servicios (Tabla 4); en la Universidad César Vallejo, tutela los derechos de los miembros de la comunidad universitaria $y$ vela por el mantenimiento del principio de autoridad responsable; en la Universidad de Guayaquil, garantiza el debido proceso establecido en el artículo 76 la Constitución (Constitución de la República del Ecuador, 2008).

\section{Labor por realizar}

En la Universidad de Málaga, tiene la labor de mediar y conciliar, previa aceptación de las partes; en la Universidad César Vallejo, no se aborda la mediación; en la Universidad de Guayaquil, existe mediación como función reglamentada.

\section{Forma de elección}

En España, le corresponde al claustro universitario, propuesta del Rector, por mayoría simple y su mandato coincidirá con el órgano colegiado; en Perú, la designación le corresponde a la Junta General de Accionistas; en ecuador, son designados por los miembros del Consejo Universitario.

\section{Forma de actuar}

En la Universidad de Málaga, Goza de independencia y autonomía, no está sometida a mandato alguno de cualquier instancia universitaria; en la Universidad César Vallejo, depende jerárquicamente del Rector; en la Universidad de Guayaquil, depende jerárquicamente del Rector. 
Tabla 4. Constitución de la Defensoría Universitaria: Proceso para la resolución de los conflictos de los servidores administrativos y de servicio.

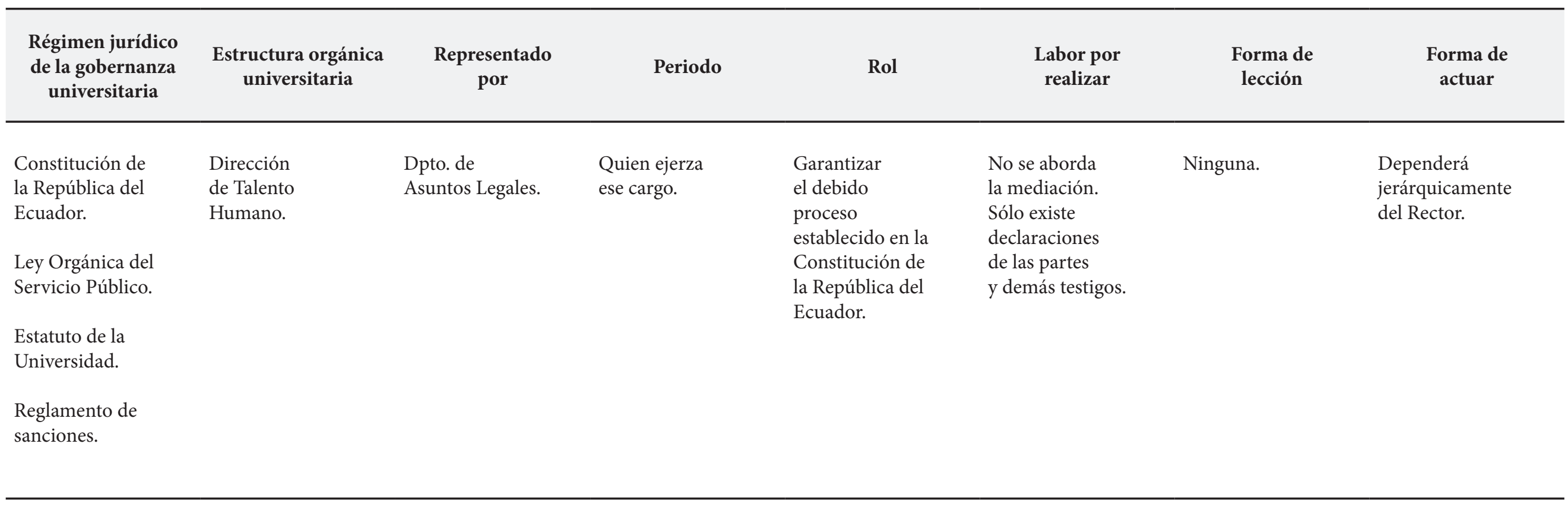


Tabla 5. Cuadro comparativo de la constitución de la defensoría universitaria.

\begin{tabular}{|c|c|c|c|c|c|c|c|c|}
\hline Universidades & $\begin{array}{l}\text { Régimen jurídico } \\
\text { de la gobernanza } \\
\text { universitaria }\end{array}$ & $\begin{array}{c}\text { Estructura } \\
\text { orgánica } \\
\text { universitaria }\end{array}$ & Representado por & Periodo & Rol & Labor por realizar & Forma de elección & Forma de actuar \\
\hline Málaga & $\begin{array}{l}\text { Constitución } \\
\text { Española. } \\
\text { Ley Orgánica de } \\
\text { Universidades. } \\
\text { Estatuto de la } \\
\text { Universidad. } \\
\text { Reglamento } \\
\text { del Defensor } \\
\text { Universitario. }\end{array}$ & $\begin{array}{l}\text { Órgano } \\
\text { unipersonal. } \\
\text { Ostentará } \\
\text { rango de } \\
\text { Vicerrectorado } \\
\text { como forma } \\
\text { protocolaria en } \\
\text { el ejercicio de la } \\
\text { defensoría. }\end{array}$ & $\begin{array}{l}\text { Defensor } \\
\text { Universitario. } \\
\text { Puesto que será } \\
\text { desempeñado } \\
\text { por un integrante } \\
\text { de la comunidad } \\
\text { universitaria } \\
\text { con vinculación } \\
\text { permanente, } \\
\text { de prestigio } \\
\text { y trayectoria } \\
\text { profesional. }\end{array}$ & $\begin{array}{l}4 \text { años y existe } \\
\text { reelección. }\end{array}$ & $\begin{array}{l}\text { Garantizar y } \\
\text { proteger los } \\
\text { derechos y las } \\
\text { libertades del } \\
\text { profesorado, } \\
\text { estudiantes, } \\
\text { personal de } \\
\text { administración y } \\
\text { servicios. }\end{array}$ & $\begin{array}{l}\text { Mediación y } \\
\text { conciliación, } \\
\text { previa aceptación } \\
\text { de las partes. }\end{array}$ & $\begin{array}{l}\text { Corresponde } \\
\text { al Claustro } \\
\text { Universitario, } \\
\text { a propuesta } \\
\text { del Rector, por } \\
\text { mayoría simple } \\
\text { y su mandato } \\
\text { coincidirá con el } \\
\text { órgano colegiado. }\end{array}$ & $\begin{array}{l}\text { Gozará de } \\
\text { independencia } \\
\text { y autonomía, no } \\
\text { estará sometida a } \\
\text { mandato alguno } \\
\text { de cualquier } \\
\text { instancia } \\
\text { universitaria. } \\
\text { Con rendición de } \\
\text { cuentas. }\end{array}$ \\
\hline César Vallejo & $\begin{array}{l}\text { Constitución } \\
\text { Política del } \\
\text { Perú. } \\
\text { Ley Universitaria } \\
\text { Ley No. } 30220 . \\
\text { Estatuto de la } \\
\text { Universidad. } \\
\text { Reglamento } \\
\text { General de la } \\
\text { Universidad. }\end{array}$ & $\begin{array}{l}\text { Órgano de } \\
\text { Línea del } \\
\text { Vicerrectorado } \\
\text { de Bienestar } \\
\text { Universitario. } \\
\\
\text { Dirección de } \\
\text { Defensoría } \\
\text { Universitaria. }\end{array}$ & $\begin{array}{l}\text { Defensor } \\
\text { Universitario. } \\
\text { Puesto que será } \\
\text { desempeñado } \\
\text { por un director } \\
\text { designado por } \\
\text { el directorio de } \\
\text { la Junta General } \\
\text { de Accionistas, } \\
\text { depende } \\
\text { jerárquicamente } \\
\text { del Rector. }\end{array}$ & No se indica. & $\begin{array}{l}\text { Tutelar los } \\
\text { derechos de los } \\
\text { miembros de } \\
\text { la comunidad } \\
\text { universitaria } \\
\text { y velar por el } \\
\text { mantenimiento } \\
\text { del principio } \\
\text { de autoridad } \\
\text { responsable. }\end{array}$ & $\begin{array}{l}\text { No se aborda } \\
\text { la mediación. }\end{array}$ & $\begin{array}{l}\text { Designación } \\
\text { corresponde } \\
\text { a la Junta } \\
\text { General de } \\
\text { Accionistas. }\end{array}$ & $\begin{array}{l}\text { Dependerá } \\
\text { jerárquicamente } \\
\text { del Rector. }\end{array}$ \\
\hline
\end{tabular}




\begin{tabular}{|c|c|c|c|c|c|c|c|c|}
\hline Universidades & $\begin{array}{l}\text { Régimen jurídico } \\
\text { de la gobernanza } \\
\text { universitaria }\end{array}$ & $\begin{array}{l}\text { Estructura } \\
\text { orgánica } \\
\text { universitaria }\end{array}$ & Representado por & Periodo & Rol & Labor por realizar & Forma de elección & Forma de actuar \\
\hline $\begin{array}{l}\text { Universidad } \\
\text { de Guayaquil }\end{array}$ & $\begin{array}{l}\text { Constitución de } \\
\text { la República del } \\
\text { Ecuador. } \\
\text { Ley Orgánica } \\
\text { de Educación } \\
\text { Superior. } \\
\text { Estatuto de la } \\
\text { Universidad. } \\
\text { Reglamento de } \\
\text { Sanciones. }\end{array}$ & $\begin{array}{l}\text { Consejo } \\
\text { Universitario. }\end{array}$ & $\begin{array}{l}\text { Comisión del } \\
\text { Debido Proceso, } \\
\text { designado por } \\
\text { el Consejo } \\
\text { Universitario. }\end{array}$ & Permanente. & $\begin{array}{l}\text { Garantizar el } \\
\text { debido proceso } \\
\text { establecido en la } \\
\text { Constitución de } \\
\text { la República del } \\
\text { Ecuador en su } \\
\text { Art. } 76 .\end{array}$ & $\begin{array}{l}\text { La medición es } \\
\text { reglamentada. }\end{array}$ & $\begin{array}{l}\text { Designados por } \\
\text { los miembros } \\
\text { del Consejo } \\
\text { Universitario. }\end{array}$ & $\begin{array}{l}\text { Dependerá } \\
\text { jerárquicamente } \\
\text { del Rector. }\end{array}$ \\
\hline
\end{tabular}




\section{CONCLUSIONES}

Se evidencia que, si bien es cierto que las normativas jurídicas de España abren el abanico para garantizar y proteger los derechos y libertades de la comunidad universitaria, a través del Defensor Universitario, quien utiliza como herramienta de gestión la mediación, también es cierto que en Perú se implementa la Oficina del Defensor Universitario, que se encuentran contempladas en sus leyes, sin embargo, dentro de su estructura orgánica administrativa, así como los estatutos y reglamentos, no tienen bien definidas las funciones del defensor ya que no se estipula qué se debe trabajar con la mediación para la resolución de los problemas en la comunidad universitaria. Por otra parte, en el Ecuador, las acciones para la resolución de los conflictos, no se encuentran presentes en la estructura orgánica ni tampoco en las normativas jurídicas que regulen la alternativa del mecanismo de la mediación como forma de resolver los problemas.

Una vez analizado el panorama de la figura del Defensor Universitario para la mediación, en los países como España, Perú y Ecuador, se concluye que, las universidades estudiadas del Perú deberían fortalecer este mecanismo alternativo como es la mediación, teniendo claro cuáles son las atribuciones y competencias del defensor, en especial, el goce de la autonomía e independencia de otros organismos internos, que coadyuve a la resolución de los problemas sin que medie ninguna intervención de orden político, de tal manera, que garantice y se protege como debe ser los derechos y libertades contempladas en la Carta Magna.

Por otra parte, en Ecuador, en la Universidad de Guayaquil existe el mediador de conflictos, sin embargo, no existe la figura del Defensor
Universitario para que las medidas que se tomen frente a los conflictos en el interior de la comunidad universitaria no lleguen a situaciones de tipo legal, y esto, se puede lograr cuando se alcance un grado de concienciación que la mediación es una alternativa que coadyuva a la convivencia pacífica y armónica. Sin dejar de obviar, que las características principales de un mediador deben ser la de gozar de independencia, credibilidad y sobre todo confianza para poder mediar, con la finalidad de resolver los conflictos dentro de los contextos universitarios.

REFERENCIAS

Alcover de la Hera, C. M. (2019). Alternativas de mediación en contextos universitarios: una propuesta de modelo contingente y sus aplicaciones en la resolución de conflictos a través de la figura del defensor universitario. Madrid: COLEX. doi: 978-84-8342-224-3

B.O.E. (21 de diciembre de 2001). Ley Orgánica 6/2001. Obtenido de Ley Orgánica 6/2001: https://www.boe.es/buscar/pdf/2001/BOE-A2001-24515-consolidado.pdf

BOE Ministerio de Educación. (31 de diciembre de 2010). Legislación consolidada. (318), 12 - 23. España

BOJA. (17 de mayo de 2019). Boletín Oficial de la Junta de Andalucía. (93), 157. Andalucía, España: BOJA

Cepeda Ruiz, J. B. (2019). Condiciones necesarias y legales para el desempeño eficaz de la defensoría universitaria en el Perú. Perspectiva de la comunidad universitari. Trujillo, Perú. Trujillo, Perú: repositorio de la Universidad Nacional de Trujillo. Obtenido de http://repositorio. upao.edu.pe/bitstream/upaorep/5619/1/RE_ DOCT_EDU_JOS\%C3\%89.C\%C3\%89PEDA_ DESEMPE\%C3\%91O.EFICAZ_DATOS.PDF

Congreso de la República. (3 de julio de 2014). LEY UNIVERSITARIA No. 30220. Obtenido de LEY UNIVERSITARIA No. 30220: http://www. minedu.gob.pe/reforma-universitaria/pdf/ley_ universitaria.pdf 
Congreso Nacional. (Octubre de 2008). Constitución de la República del Ecuador. Obtenido de Constitución de la República del Ecuador: https://educacion.gob.ec/wp-content/ uploads/downloads/2012/08/Constitucion.pdf

de Armas Hernández, M. (2003). Educar, 32(125 136)

Gaddi, D. (septiembre de 2016). La mediacipon reflexiva como mecanismo de regulación social. Bellaterra, España

Ley Orgánica de Educación Superior. (12 de octubre de 2010)

LOES. (DICIEMBRE de 12 de 2016). LEY ORGANICA DE EDUCACION SUPERIOR, LOES. Recuperado el 22 de mayo de 2017, de LEY ORGANICA DE EDUCACION SUPERIOR, LOES: https://n9.cl/pr70

Miranzo de Mateo, S. (2010). QUIÉNES SOMOS, A DÓNDE VAMOS... ORIGEN Y EVOLUCIÓN DEL CONCEPTO MEDIACIÓN. Revista de Mediación, 3(5). Obtenido de http://www.ammediadores.es/ nueva/wp-content/uploads/2014/12/5.1 QUI\%C3\%89NES-SOMOS-A-D\%C3\%93NDEVAMOS\%E2\%80\%A6.pdf

Reglamento General de la Universidad César Vallejo S.A.C. (s.f.). Resolución de Director No. 040-2015. Perú
Schriewer, J. (2002). Educación comparada: un gran programa ante nuevos desafíos. Formación del discurso en la educación comparada, 13-40. Obtenido de https://bit.ly/2JYEooh

Universidad Autónoma de Nuevo León. (2019). En L. t. México. Moterrey

Universidad César Vallejo. (12 de noviembre de 1991). Ley de creación de la Universidad César Vallejo. Obtenido de Ley de creación de la Universidad César Vallejo: https://bit.ly/31r877e

Universidad César Vallejo. (05 de mayo de 2017). Estatuto de la Universidad César Vallejo S.A.C. Obtenido de Estatuto de la Universidad César Vallejo S.A.C.: https://www.ucv.edu.pe/ datafiles/TRANSPARENCIA/ESTATUTO $\% 20$ UCV/ESTATUTO\%20V03.pdf

Universidad de Guayaquil. (18 de febrero de 2019). Estatuto de la Universidad de Guayaquil. Obtenido de Estatuto de la Universidad de Guayaquil: https://bit.ly/3kq318L

Universidad de Málaga. (s/d de febrero de 2013). Reglamento de Defensor de la comunidad universitaria. Obtenido de Reglamento de Defensor de la comunidad universitaria: https:// bit.ly/2GWh8WW 